\title{
MOVIMENTAÇÃO DE ESTOQUES (PEPS E CUSTO MÉDIO) E SEUS IMPACTOS FINANCEIROS E ECONÔMICOS NAS ENTIDADES COMERCIAIS
}

\section{ARTIGO ORIGINAL}

SILVA, Erick Cristiano Lima da ${ }^{1}$, SILVA, Wallace Alves $\mathrm{da}^{2}$, COUTINHO, Gleice Dias $^{3}$, VIEIRA, Suelen Galvão ${ }^{4}$, ROBERTO, José Carlos Alves ${ }^{5}$, SERRA, Meg Rocha da Cunha $^{6}$, LOPES, Nelânia Ferreira ${ }^{7}$

SILVA, Erick Cristiano Lima da. Et al. Movimentação de estoques (PEPS e custo médio) e seus impactos financeiros e econômicos nas entidades comerciais. Revista Científica Multidisciplinar Núcleo do Conhecimento. Ano 06, Ed. 11, Vol. 05, pp. 124-144. Novembro de 2021. ISSN: 2448-0959, Link de acesso: https://www.nucleodoconhecimento.com.br/contabilidade/movimentacaode-estoques,

DOI:

10.32749/nucleodoconhecimento.com.br/contabilidade/movimentacao-de-estoques

\section{RESUMO}

Neste artigo será tratado a respeito dos estoques, sua movimentação e controle. O estoque é um ativo que tem grande participação no funcionamento de uma entidade, armazenando insumos para a produção ou itens prontos para a venda. Assim, precisam de gerência na sua organização e tratamento, objetivando os resultados que deles se esperam e dos que são alcançados. Para compreender com clareza o

\footnotetext{
${ }^{1}$ Graduando do curso de Contabilidade.

${ }^{2}$ Graduando do curso de Contabilidade.

${ }^{3}$ Graduando do curso de Contabilidade.

${ }^{4}$ Graduando do curso de Contabilidade.

${ }^{5}$ Orientador. Mestre em Engenharia de produção. Especialista Logística empresarial. Graduado em Administração com Ênfase em Marketing.

${ }^{6}$ Orientadora. Mestra em Engenharia de Processos Industriais pela UFPA, especialista em Controladoria e Auditoria Contábil pelo Ciesa (2020), Graduada em Ciências Contábeis pelo Centro Universitário do Norte (2010). Graduada em Ciências Econômicas pelo Centro Universitário do Norte (2006).

${ }^{7}$ Orientadora. Especialista em Auditoria Contábil, Financeira e Tributaria e Graduada em Ciências Contábeis.
}

RC: 100873

Disponível em:

https://www.nucleodoconhecimento.com.br/contabilidade/movimentacao-deestoques 
assunto definiu-se a seguinte problemática: Como controlar os estoques e em que dimensões dentro das entidades eles causam impactos? Nesse contexto, o estudo tem o objetivo de abordar sobre as movimentações, controle dos estoques e os impactos que causam em diferentes esferas das entidades. A pesquisa classifica-se como explicativa e o levantamento dos dados foi realizado por meio de uma pesquisa bibliográfica. Os dados foram levantados e analisados por meio da técnica de análise de conteúdo e caracteriza-se como uma pesquisa qualitativa. Constatouse que a entidade deve trabalhar seus estoques da maneira que melhor se adeque ao seu funcionamento, não deixando de dar a devida importância ao gerenciamento dos estoques, buscando eficiência, otimização e um bom desempenho. Espera-se que este artigo possa servir de base acadêmica para futuros trabalhos, e, em uma perspectiva profissional para quem procura informações a respeito deste tema.

Palavras-chave: Estoque, movimentação, PEPS, custo médio, impactos.

\section{INTRODUÇÃO}

O presente artigo é um estudo bibliográfico direcionado para o estoque. Para Gelbcke (2018) ao se classificar estoque, em um sentido direto, determinam-no como um ativo, uma conta patrimonial onde, no balanço, é explicitado através de uma contabilização que the agrega o valor que possui. Estoques são investimentos, são aplicações de valores monetários de onde se espera que venha a ter retorno financeiro positivo, portanto, também é capital de giro, um recurso a ser convertido em receita. Dessa forma, se espera que os estoques funcionem como uma garantia para com o equilíbrio e pleno funcionamento da entidade a qual pertence.

O movimento dos estoques compreende todo o percurso que esse ativo faz, desde a sua aquisição até chegar às mãos do consumidor final. Movimento que não é apenas físico ou operacional, pois também adentra na esfera econômica, financeira, administrativa e patrimonial, e assim se pode dizer que há toda uma sinergia advinda do tratamento dos estoques. O método PEPS e Custo Médio são meios de

RC: 100873

Disponível em:

https://www.nucleodoconhecimento.com.br/contabilidade/movimentacao-deestoques 
controle, tanto físico quanto financeiro, que permitem aos gestores terem uma visão do todo nas suas operações e que de certa forma contribuem para um ótimo desempenho da empresa. Dessa forma, será abordado sobre a movimentação e o controle dos estoques, além dos impactos que eles causam em diferentes esferas das entidades.

Para Marconi e Lakatos (2017), a formulação de um problema é algo de grande especificidade quando se busca a resolução de alguma dificuldade e será justamente essa questão que irá nortear os rumos da pesquisa. Dessa forma, como controlar os estoques e em que dimensões dentro das entidades eles causam impactos?

Para o desenvolvimento do presente trabalho foram utilizadas pesquisas bibliográficas, baseadas em livros, além do CPC 16 (Comitê de Pronunciamentos Contábeis) que permitiram o embasamento técnico na elaboração deste. Sua natureza será qualitativa e sob ótica dos objetivos será explicativa, devido às características do projeto que visam abordar o estoque e o seu controle.

Para que tal objetivo seja alcançado certas questões intermediárias foram tratadas para permitir o entendimento deste assunto: examinar conteúdo bibliográfico, a fim de correlacionar com a movimentação de estoques; analisar a cinética envolvida no controle e valoração dos estoques (Peps e Custo Médio); e tratar sobre as dimensões que sofrem influência da movimentação dos estoques.

Este trabalho busca levar à comunidade acadêmica todo um referencial teórico relativo à gestão e movimentação de estoques, capazes de garantir ferramentas eficientes e eficazes nas organizações e servir como base de futuros trabalhos acadêmicos que possuam como temática os estoques das organizações. Visa levar também uma gama de conhecimento aos profissionais da área de gestão de estoques com o intuito estimular novas abordagens, estudos e aperfeiçoamento das ferramentas de gestão de estoques apresentados, auxiliando o desenvolvimento e a sobrevivência das entidades no mercado.

RC: 100873

Disponível em:

https://www.nucleodoconhecimento.com.br/contabilidade/movimentacao-deestoques 


\section{FUNDAMENTAÇÃO TEÓRICA}

O referencial teórico deste artigo foi estruturado em seis tópicos: Contabilidade, Conceito de estoque, Entidades Comerciais, Gestão de estoques, Métodos de controle e valoração, Impactos do tratamento dos estoques.

De acordo com Marconi e Lakatos (2017), a fundamentação teórica em uma pesquisa científica é aquela responsável pelas validações e instruções do trabalho, onde, no decorrer da interpretação dos fatos/objetos da pesquisa, trarão o embasamento teórico necessário para o autor no desenvolvimento da pesquisa e nos resultados obtidos.

\subsection{CONTABILIDADE}

$\mathrm{Na}$ antiguidade o homem necessitava de um sistema de controle e mensuração dos meios de produção, bem como saber de todos os fatores que poderiam influenciar na sua produtividade. Por exemplo, de uma produção rural de animais, o clima e a região eram primordiais para o planejamento da produção, que devido à época seriam bastante imprevisíveis e podiam contar somente com o senso comum (MARION, 2013).

De acordo com Marion (2013), desde o início da civilização, entre 6.000 a.C e 4.000 a.C, o homem já necessitava de um controle das suas riquezas, tais como: rebanhos, lã (derivada da criação de ovelhas), utensílios de uso. Tais riquezas geradas serviam tanto para a manutenção própria da sua atividade principal, quanto como moeda de troca para outras necessidades da sua sobrevivência como equipamentos de caça e pesca. Contudo, nesse período, não havia números para quantificar e nem escrita para registrar os fatos, desta forma, o patrimônio era quantificado de maneira bem rústica com imagens, desenhos, figuras etc. E foi frente a essa situação que o objetivo da contabilidade surgiu, o qual visa controlar o patrimônio, além dos fundamentos de inventário, que é quantificar o patrimônio.

RC: 100873

Disponível em:

https://www.nucleodoconhecimento.com.br/contabilidade/movimentacao-de$\underline{\text { estoques }}$ 


\subsubsection{CONTABILIDADE DE CUSTOS}

Na visão de Silva e Lins (2014), a Contabilidade de Custos surge em decorrência do aumento da competitividade trazida pela globalização dos mercados. Agravado pelas crises mundiais, as demandas do mercado foram se tornando cada vez maiores e as empresas tiveram de se reinventar em seus segmentos, procurando ferramentas mais eficientes e eficazes, tanto de gestão como de métodos, com o intuito de reduzir os custos do negócio, a fim de sobreviverem e manterem os seus negócios em um cenário de redução das vendas e baixa lucratividade.

Na visão de Silva e Lins (2014), a Contabilidade de Custos surge em decorrência ao aumento da concorrência entre as empresas trazidas pela globalização dos mercados e agravados pelas crises mundiais, demandando em mercados cada vez mais competitivos e as empresas devem se reinventarem em seus segmentos, procurando ferramentas mais eficientes e eficazes tanto de gestão como de métodos, com o intuito de redução dos custos do negócio objetivando a sobrevivência e manutenção da empresa em um cenário de redução das vendas e baixa lucratividade.

O conceito de contabilidade de custos está ligado às técnicas de identificação e mensuração dos custos de produtos e serviços com o objetivo de fornecer informações precisas à gestão para o melhor acompanhamento e tomada de decisão relativas à entidade (SILVA e LINS, 2014).

\subsection{CONCEITO DE ESTOQUE}

Os Estoques são um dos ativos mais importantes que compõem o patrimônio de uma entidade, são mantidos sobre o domínio desta para que futuramente sejam convertidos em valores monetários através dos processos comerciais aplicados pela entidade, assim, é uma conta mantida no balanço patrimonial como um ativo circulante, um bem que fica disponível para geração de Receita e que também

RC: 100873

Disponível em:

https://www.nucleodoconhecimento.com.br/contabilidade/movimentacao-de$\underline{\text { estoques }}$ 
compõe o capital de giro da instituição e representa diretamente a aplicação de recursos financeiros.

O CPC (2009) discorre sobre os Estoques, atribuindo-Ihe o status de ativo, na contabilidade, tratando-o com certas características: como produtos, que podem passar ou não - estando já prontos para a venda - por algum processo de transformação, como insumos a serem consumidos através destes processos ou no decorrer dos serviços oferecidos. Sendo assim, itens que são acondicionados, armazenados para serem utilizados nos trâmites usuais dos negócios.

Por mais que os objetivos de seu uso Ihe concedam uma característica de liquidez, do qual se espera que haja retorno, para Gelbcke (2018), o estoque é visto como um bem de propriedade tangível. Além disso, é um recurso que está sob o domínio e controle da entidade, possuindo então um valor monetário que pode ser contabilizado e trazer benefícios.

De acordo com Marion (2013), a definição de ativo possui várias interpretações entre os autores, porém a mais comum é: o ativo é o conjunto de bens e direitos que estão à disposição da entidade. Outras variações também são bem aceitas como que, o ativo são os meios pelo qual a administração utiliza-se para gestão da entidade.

O grupo de Ativo de uma entidade divide-se em ativo circulante e ativo não circulante. A conta de estoques está registrada no ativo circulante, pelo motivo de os valores desta conta serem realizados no prazo de um ano a contar da data do Balanço Patrimonial. Sendo assim, entende-se também dessa divisão, o fato das contas do ativo estarem agrupadas em ordem decrescente do grau de liquidez (rapidez com que o item pode ser convertido em moeda corrente).

$\mathrm{Na}$ visão de Almeida (2014), nas entidades, os estoques representam ativos que dependendo do ramo empresarial e podem ser estoques de empresas comerciais, os quais são adquiridos de outras empresas e que já estão acabados e no ponto de serem revendidos aos clientes; ou estoques de empresas industriais, aqueles que

RC: 100873

Disponível em:

https://www.nucleodoconhecimento.com.br/contabilidade/movimentacao-deestoques 
passarão por processo produtivo até chegar no produto acabado, o qual será posto à venda.

\subsection{ENTIDADES COMERCIAIS}

Martins (2015) observa que a empresa comercial surgiu da necessidade de organização advindas das demandas do comércio e que é difícil encontrar uma definição para ela, devido à natureza de suas atividades. No entanto, a empresa comercial pode ser caracterizada a partir do ponto de vista de seu funcionamento e objetivo, pelo qual ela vem a existir. Já o empresário, atuando profissionalmente, realiza a circulação de bens de uma pessoa para outra, com a finalidade de obter lucro. Aqueles que mantêm estoque de mercadorias as vendem a quem destas precisam, em troca de moeda, ou seja, valor monetário.

De acordo com Gelbcke (2018) as empresas comerciais, assim como as industriais, não funcionam sem que possuam estoques, pois são ativos circulantes de muita importância e que fazem girar a vida econômica das entidades, desde que utilizados os métodos assertivos no começo e no fim do período contábil para a correta apuração do lucro contábil e para elaboração dos demonstrativos de gestão financeira e patrimonial da empresa. Por outro lado, exercendo suas atividades por meio da oferta de produtos e demanda do mercado consumidor, a operação do negócio desempenha papel de grande relevância na sociedade e na economia do país.

O objetivo desta parceria nada mais é do que fazer com que seus estoques tenham movimentação diária, trazendo lucratividade e evitando a baixa circulação e gastos desnecessários

As Entidades Comerciais que comercializam produtos precisam ter um controle de estoque.

RC: 100873

Disponível em:

https://www.nucleodoconhecimento.com.br/contabilidade/movimentacao-deestoques 


\subsection{GESTÃO DE ESTOQUES}

Como descrito por ludícibus e Marion (2010), em um cenário hipotético em que uma empresa não venda suas mercadorias o estoque final não sofreria modificações, sendo assim, permaneceria constante, visto que a soma do seu estoque inicial com suas compras permaneceria igual, o que de fato não ocorre na prática nas empresas, pois há bastante modificações no estoque devido ao grande volume das compras e vendas durante seu processo produtivo e comercial.

Já que os estoques são os ativos que geram receita à entidade, é de vital importância que o seu gerenciamento evite erros que possam acarretar perdas financeiras e econômicas, com a adoção de um critério que permita ter a ampla visão do montante (valor, quantidade), já que os estoques devem ser mantidos dentro de níveis equilibrados, ou seja, não podem estar em quantias inferiores ou superiores ao necessário. Assim, pode-se constatar a busca por eficiência e, principalmente, se a sua valoração está em um nível de suprir as necessidades da entidade (do quanto vale, do quanto pode se obter com o produto), permitindo assim que a oferta satisfaça a variação da demanda, já que se não há oferta não há geração de receita, procurando atingir níveis ótimos de serviço.

Silva (2018) destaca que uma empresa quando está ciente do nível de serviço que deseja alcançar ou manter, pode utilizar a gestão de estoque como uma ferramenta estratégica que irá definir o melhor manuseio do estoque de acordo com seus objetivos. Através das decisões empreendidas, a gestão de estoque permite definir a disponibilidade do produto, ou a forma como esse será mantido, buscando o melhor posicionamento possível, deixando assim o estoque organizado de maneira eficiente.

De acordo com Paoleschi (2019), é realmente importante que uma empresa tenha o devido cuidado quanto a gestão dos seus estoques, visto que ao trabalhar com estoque é necessário que haja todo um planejamento estratégico e operacional,

RC: 100873

Disponível em:

https://www.nucleodoconhecimento.com.br/contabilidade/movimentacao-deestoques 
ponto fundamental para que uma boa gestão ocorra, a fim de se evitar acontecimentos que irão prejudicar a entidade. O planejamento e a gestão podem manter níveis de estoque que satisfaçam a oferta e a demanda, e com isso evite custos desnecessários, pois permite que não haja desperdício de tempo e de espaço.

Todos esses controles geram dados e demonstram resultados, eficiência e eficácia, que incidem em diversas dimensões ou esferas dentro de uma entidade, tais como decisões a serem tomadas, objetivos a serem alcançados, procedimentos a serem adotados e a melhor técnica a ser empreendida, demonstrando assim, um grande impacto gerencial em diferentes níveis dentro da entidade.

\subsection{MÉTODOS DE CONTROLE E VALORAÇÃO}

Ferreira (2014) elucida que quando um estoque passa a ter uma gama de itens, esses que por sua vez serão comercializados, trocados, substituídos ou repostos, ou seja, que sofrerão constantes modificações em seus montantes, sendo esta uma característica inerente aos estoques, é preciso adotar um método que vá direcionar a correta valoração dos itens que ali são mantidos. Para este critério deve ser levado em consideração aspectos que visem uma padronização como os traços da natureza do item e semelhanças quanto ao uso, ou seja, os itens do estoque devem ser valorizados através de um mesmo método conforme suas características.

Conforme discorrem ludícibus e Marion (2010), o inventário permanente é uma ferramenta capaz de demonstrar o dinamismo da movimentação dos estoques e de onde se pode extrair uma gama de informações, já que permite a visualização operacional e financeira dos estoques, assim então, a cada vez que uma venda é realizada, em contrapartida, a saída deste determinado produto vendido é controlado no estoque, o mesmo funciona para a aquisição de produtos, gerando assim uma cadeia de ação e reação. Quando estes fatos são monitorados, levando em consideração não apenas as quantidades dos itens, mas também seus valores, é

RC: 100873

Disponível em:

https://www.nucleodoconhecimento.com.br/contabilidade/movimentacao-deestoques 
possível conhecer o Custo de Mercadoria Vendida (CMV), assim como o valor total do estoque que ainda permanece sobre a posse da entidade, a fim de ser comercializado.

No entanto, ludícibus e Marion (2010) acrescentam que, apesar do inventário permanente trazer benefícios como maior controle nos estoques, sua adoção possui a desvantagem de exigir um acompanhamento constante e efetivo de todos os itens do estoque, o que, dependendo do porte da empresa, pode acarretar maior custo de pessoal (controle manual) e em processamento de dados para o devido tratamento das informações, a fim de acompanhar as flutuações de cada item do estoque negociado.

\subsubsection{PEPS}

O método de controle PEPS (Primeiro que entra, primeiro que sai) ou do original inglês FIFO (First in, First Out), como a nomenclatura sugere, é um processo pelo qual os estoques são processados e controlados partindo da ideia de que o produto a ser oferecido deve ser impreterivelmente aquele que foi adquirido primeiramente. Tal método utiliza uma cronologia, em que os itens mais antigos saem primeiro e são sucedidos para a oferta pelos itens adquiridos posteriormente. Isso cria uma cadeia de sucessão, pois ao considerar cada nova compra para os estoques como um critério para sua organização, permite que o estoque, como uma conta no balanço patrimonial, esteja sempre com seus valores mais atualizados.

O CPC (2009) dispõe sobre a ordem de aquisição ou produção, venda e compra dos itens de estoque em relação a como estes serão disponibilizados no mercado, conforme o critério PEPS. Dessa forma, todos os itens que serão vendidos devem seguir uma ordem específica de venda e uma ordem de permanência dos itens no estoque, criando, portanto, uma linha temporal que prioriza, para a comercialização, os itens mais antigos em detrimento dos mais novos, tendendo estes últimos, ao

RC: 100873

Disponível em:

https://www.nucleodoconhecimento.com.br/contabilidade/movimentacao-deestoques 
final de um determinado período, a permanecerem no estoque aguardando futuras negociações.

Conforme Ferreira (2014), o caráter financeiro do critério PEPS ou no inglês FIFO, leva em conta que as unidades mais antigas dos estoques serão vendidas primeiramente, portanto, todos os valores desprendidos para a sua aquisição, no fim, irão formar o valor do Custo de Mercadoria Vendida (CMV), o que contribui diretamente para a análise de resultados e precificação do produto. Sendo assim, os itens que permanecem nos estoques serão aqueles adquiridos mais recentemente $e$ serão justamente estes que irão compor o valor do estoque final.

\subsubsection{DEMONSTRATIVO PEPS}

No desenvolvimento da ilustração utiliza-se a Ficha de controle de estoques (ficha Kardex), e no primeiro momento registra-se a compra pelo seu valor de custo. Portanto, temos no dia 01/04 compras de 100 unidades de produtos, ao valor unitário de $R \$ 10,00$, totalizando $R \$ 1.000,00$, já em $15 / 04$ uma compra de 150 unidades de produtos ao valor unitário de $R \$ 12,00$, totalizando $R \$ 1.800,00$. Ressalta-se que, para os critérios de valoração de estoques, o mais importante é o custo das saídas ou simplesmente saídas na Ficha de controle. A primeira saída ou venda foi de 50 unidades, neste momento, o importante é a aplicação do método PEPS que diz: o primeiro item do estoque que entra será o primeiro a sair. Seguindo essa linha de raciocínio, no dia 01/04 foram compradas 100 unidades a $R \$ 10,00$, logo, o custo de 50 unidades vendidas será de $R \$ 500,00$ (50 x $R \$ 10,00)$. Na segunda saída, após o registro da compra do dia 20/04 tínhamos em estoque 500 unidades totais. No dia 30/04 foram vendidas 450 unidades, onde de acordo com a ficha de controle sobraram 50 unidades de $R \$ 10,00,150$ unidades de $R \$ 12,00$ e 250 unidades de $R \$ 15,00$, com isso, é preciso baixar seus custos, até que chegue nas 450 unidades vendidas ou saídas. Após todos os registros das movimentações, chega-se ao estoque final com 50 unidades de $R \$ 15,00$ de valor unitário, totalizando o valor de $\mathrm{R} \$ 750,00$.

RC: 100873

Disponível em:

https://www.nucleodoconhecimento.com.br/contabilidade/movimentacao-deestoques 
Tabela 1: Método PEPS

\begin{tabular}{|c|c|c|c|c|c|c|c|c|c|c|}
\hline \multicolumn{5}{|c|}{ Entradas } & \multicolumn{3}{|c|}{ Saidas } & \multicolumn{3}{|c|}{ Saldos } \\
\hline \multirow{2}{*}{\begin{tabular}{|l|} 
Data \\
$01 / 04 / 2021$ \\
\end{tabular}} & \multirow{2}{*}{\begin{tabular}{|l|} 
Histórico \\
Compra \\
\end{tabular}} & \multirow{2}{*}{$\begin{array}{l}\text { Qtde. } \\
100\end{array}$} & \multicolumn{2}{|c|}{ Preço Unit.Valor } & \multirow[t]{2}{*}{ Qtde. } & Preço Unit. & \multirow[t]{2}{*}{ Valor } & \multirow{2}{*}{$\begin{array}{l}\text { Qtde. } \\
100\end{array}$} & Preço Unit. & \multirow{2}{*}{\begin{tabular}{|l} 
Valor \\
R\$1.000,00
\end{tabular}} \\
\hline & & & RS 10,00 & R\$1.000,00 & & & & & RS 10,00 & \\
\hline $15 / 04 / 2021$ & Compra & 150 & RS 12,00 & R\$1.800,00 & & & & $\underline{150}$ & RS 12,00 & $\mathrm{R} \$ 1.800,00$ \\
\hline & & & & & & & & 250 & & $\mathrm{R} \$ 2.800,00$ \\
\hline \multirow[t]{3}{*}{\begin{tabular}{|l}
$16 / 04 / 2021$ \\
\end{tabular}} & Venda & & & & 50 & RS 10,00 & RS 500,00 & 50 & RS 10,00 & RS 500,00 \\
\hline & & & & & & & & $\underline{150}$ & RS 12,00 & RS1.800,00 \\
\hline & & & & & & & & 200 & & $\mathrm{R} \$ 2.300,00$ \\
\hline \multirow[t]{4}{*}{$20 / 04 / 2021$} & Compra & 300 & RS 15,00 & $\mathrm{R} \$ 4.500,00$ & & & & 50 & RS 10,00 & RS 500,00 \\
\hline & & & & & & & & 150 & RS 12,00 & $\mathrm{R} \$ 1.800,00$ \\
\hline & & & & & & & & 300 & RS 15,00 & R\$4.500,00 \\
\hline & & & & & & & & 500 & & $\mathrm{R} \$ 6.800,00$ \\
\hline \multirow[t]{4}{*}{\begin{tabular}{|l|}
$30 / 04 / 2021$ \\
\end{tabular}} & Venda & & & & 50 & RS 10,00 & RS 500,00 & & & \\
\hline & & & & & 150 & RS 12,00 & $\mathrm{R} \$ 1.800,00$ & & & \\
\hline & & & & & $\underline{250}$ & RS 15,00 & R\$3.750,00 & 50 & RS 15,00 & RS 750,00 \\
\hline & & & & & 450 & & $\mathrm{R} \$ 6.050,00$ & & & \\
\hline Totais & & & & R\$7.300,00 & & & $R \$ 6.550 .00$ & & & RS 750,00 \\
\hline
\end{tabular}

Fonte: Autoria própria

\subsubsection{CUSTO MÉDIO}

De maneira objetiva o Custo Médio é a divisão financeira, o total monetário gasto na compra do estoque, pelo quantitativo físico, total de itens armazenados, chegando a um valor de custo médio unitário dos itens que estão em estoque sendo aplicado de maneira global.

Segundo o CPC (2009), o critério do Custo Médio Ponderado, aponta determinadas particularidades que são intrínsecas a este método, como a semelhança dos itens para valoração e as circunstâncias de como a entidade opera, é o que irá determinar o modo de como serão feitos o controle e a apuração do custo dos itens. Se será através de intervalos regulares estipulados pela entidade ou toda vez que houver a aquisição ou a produção dos itens, a partir de um determinado momento, no começo ou no decorrer de um período. Os valores gastos serão condensados no custo total e posteriormente dividido pelo total de itens resultando em uma média que será usada para avaliar de maneira universal todos os itens mantidos no estoque.

RC: 100873

Disponível em:

https://www.nucleodoconhecimento.com.br/contabilidade/movimentacao-deestoques 
ludícibus e Marion (2010) indicam pontos que devem ser observados ao tratar o estoque pelo Custo Médio, para o melhor entendimento de como ocorre a valoração dos itens: novas aquisições e itens já existentes, este último sendo a quantidade já armazenada que possui um valor de custo determinado advindo da sua compra anterior, assim como os devidos valores monetários de aquisição de cada, não sendo necessariamente o mesmo devido às flutuações constantes do mercado que irão afetar o custo desses estoques e a sua valoração. Portanto, há duas óticas envolvidas para o cálculo do custo médio. Haverá uma agregação dos valores monetários de ambos, o custo do estoque existente e o da nova compra, sendo posteriormente dividido pela nova quantidade de itens formados, compondo um novo valor de custo unitário. Assim, o valor anterior será alterado mais uma vez, gerando, portanto, um novo valor a ser incorporado em cada item. Como há sempre uma troca infindável de produtos, sempre poderá haver alterações.

\subsubsection{DEMONSTRATIVO CUSTO MÉDIO}

De acordo com Padoveze (2014), no método pelo Custo Médio ou Custo Médio Ponderado, utiliza-se também a Ficha de controle de estoques nos registros das movimentações. Nesta a coluna representativa dos saldos é atualizada constantemente, visto que em cada compra efetuada pela entidade o custo médio dos itens do estoque se modifica.

Para o preenchimento da ficha de estoques, a dinâmica sofre pequenas modificações, sendo assim, no primeiro passo é necessário somar as quantidades das compras do dia 01/04 (100 unidades) e da compra do dia 15/04 (150 unidades) totalizando 250 unidades. Em seguida deve-se somar os saldos totais das 02 compras, que são: 100 unidades de $R \$ 10,00$ com um total de $R \$ 1.000,00$ e 150 unidades de $R \$ 12,00$ com um total de $R \$ 1.800,00$, resultando em $R \$ 2.800,00$. O próximo passo é dividir o total das compras de $\mathrm{R} \$ 2.800,00$ pela quantidade dos produtos em estoque em 250 unidades, resultando, portanto, no preço médio do estoque de $\mathrm{R} \$ 11,20$. Para os cálculos da Venda do dia 16/04 de 50 unidades, será

RC: 100873

Disponível em:

https://www.nucleodoconhecimento.com.br/contabilidade/movimentacao-deestoques 
aplicado o novo preço médio de $R \$ 11,20$, ficando 50 unidades vezes $R \$ 11,20$ totalizando $R \$ 560,00$. Desta forma, ressalta-se que a cada nova compra repete-se o primeiro passo para a descoberta do novo preço médio dos produtos.

Tabela 2: Método do Custo Médio

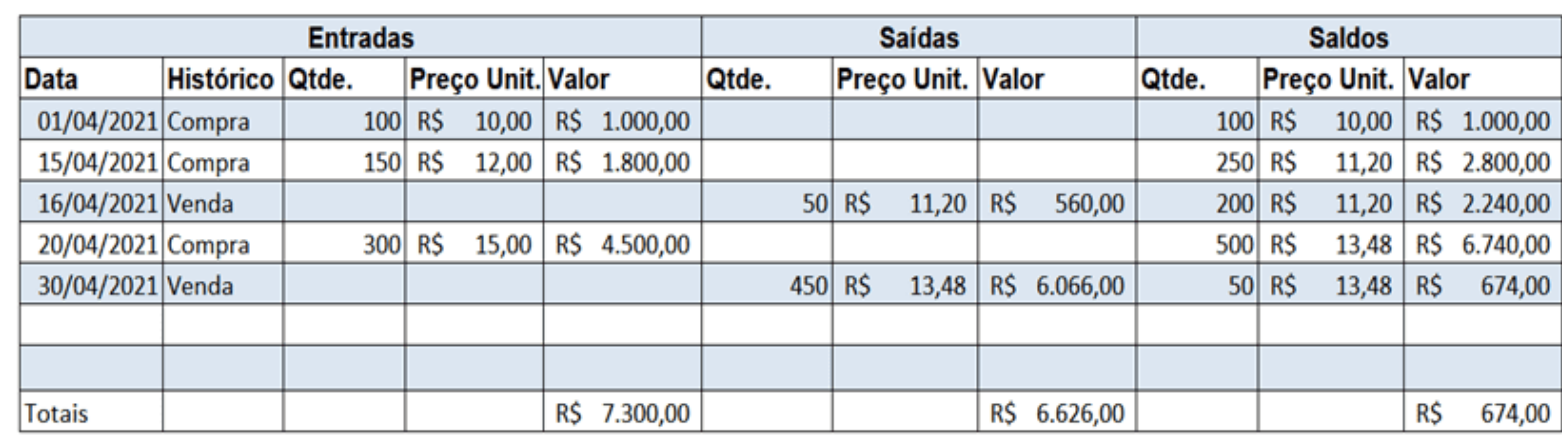

Fonte: Autoria própria

\subsection{IMPACTOS DO TRATAMENTO DOS ESTOQUES}

Paoleschi (2014) observa que devido a necessidade de gerenciamento e de como irá incorrer dentro do ambiente da empresa, o estoque vai se conectar profundamente com todas as áreas existentes que operam de forma conjunta para o funcionamento da empresa quanto às questões recorrentes de administração, controle e de como ele será contabilizado, ou seja, decisões que iram fluir de um setor a outro da entidade.

De acordo com Silva (2018), sempre há um dilema entre as diferentes áreas da empresa de como proceder com o estoque, apesar de todas precisarem trabalhar em equilíbrio, elas objetivam diferentes pontos a serem alcançados, como ter grandes quantidades de estoque para a qualidade de serviço e atendimento ao cliente, o que demanda apoio operacional e redução de estoque para evitar custos para a eficiência do fluxo de caixa, interferindo uma área na outra.

Todo o seu tratamento vai demandar uma decisão que vise o melhor aproveitamento da utilidade dos estoques. Como ativos, eles precisam gerar receita, mas para que a

RC: 100873

Disponível em:

https://www.nucleodoconhecimento.com.br/contabilidade/movimentacao-deestoques 
receita seja gerada, é preciso fazer com que eles cheguem às mãos do consumidor, precisam então gerar resultados operacionais e financeiros a fim de fazer com que a empresa, como um todo, funcione economicamente bem. Desta forma, como propriedade da empresa, estes precisam ser geridos e catalogados corretamente, posto a relevância desse patrimônio. Assim, do início ao fim o estoque é um agente modificador da empresa.

\subsubsection{IMPACTO OPERACIONAL}

Um dos impactos que pode ser melhor visualizado é na dimensão operacional, já que quando se fala em controle, organizar todo o estoque demanda grande gama de trabalho, pessoal e um sistema operacional que necessita ser alimentado com todas as informações de movimentação, aquisição, saídas e entradas. Aqui também se destaca toda a logística de transporte e armazenamento. O operacional é a via de contato com os estoques e toda a fluidez que eles possuem, sendo assim, é necessário que haja um controle efetivo, principalmente sobre essa parte, já que está ligada intimamente a produtividade, metas e ao alcance de objetivos.

Na visão de Silva (2019), a dimensão operacional é a parte em que se encontra toda dinâmica de produtividade mediante o uso dos recursos materiais e de gestão da organização, é a parte em que serão empregados esforços com a finalidade de executar o planejado com eficiência e eficácia e obter os resultados esperados pela entidade. Vale ressaltar também a importância do alinhamento das atividades empregadas que envolvem o processo produtivo e o seu gerenciamento, pois todos devem estar comprometidos estrategicamente na busca pela excelência do negócio e sua lucratividade

\subsubsection{IMPACTO FINANCEIRO}

Do outro lado, contraponto à dimensão operacional, há a dimensão financeira, ligada intimamente ao disponível da instituição, é o reflexo dos valores monetários e da alocação de recursos. Sendo os estoques um capital de giro, algo que precisou de RC: 100873

Disponível em:

https://www.nucleodoconhecimento.com.br/contabilidade/movimentacao-deestoques 
investimento para, por fim, dar retorno, o financeiro busca reduzir os níveis dos estoques fazendo com que entre receita, para assim quitar suas obrigações e despesas.

Vieira (2009) observa que existem vertentes que se contrapõem e que precisam ser balanceadas em relação ao estoque, visto que o objetivo de manter os estoques é de atender as demandas por materiais ou produtos, evitando um grande valor de recursos financeiros desprendidos com os mesmos que podem vir de aquisições, alocações, movimentações, ou seja, do tratamento dos estoques.

Silva (2019) discorre que os estoques enquanto ativos têm grande importância e vão impactar as finanças da empresa, diretamente no fluxo de caixa com a compra e venda, assim como na sua capacidade de ser convertido em receita sem perdas de valor para que a entidade possa cumprir os seus devidos deveres, o que demonstra o caráter financeiro implícito ao estoque, e como ele é uma chave cujo manuseio pode atingir bons resultados. É claro que para que o estoque atinja esse devido objetivo, seu tratamento deve ser seguido buscando o melhor aproveitamento de recursos, assim, os gastos desprendidos em sua aquisição ou produção devem sempre buscar o melhor retorno possível, evitando aquisições exacerbadas quando não há a necessidade e com o menor custo possível a fim de evitar perdas financeiras.

A legislação brasileira através de seus instrumentos de controle tributário permite três métodos para valoração de estoques, que são: custo médio, custo dos bens adquiridos ou produzidos mais recentes (método PEPS) e, por último, o custo com base no preço de vendas diminuída da margem de lucro (art.307 do RIR/2018). De acordo com Ribeiro (2011), por questões operacionais que podem elevar o custo das empresas com pessoal para um controle mais rigoroso na manutenção e gestão dos estoques (inventários periódicos) e por constantes períodos inflacionários na economia nas últimas décadas, o método mais utilizado pelas empresas brasileiras

RC: 100873

Disponível em:

https://www.nucleodoconhecimento.com.br/contabilidade/movimentacao-deestoques 
para elaboração de seus Demonstrativos de Resultado e Balanços Patrimoniais é o custo médio, por ser mais facilmente aplicável nas entidades.

Tabela 3: Comparativo PEPS e Custo Médio

\begin{tabular}{|c|c|c|c|c|}
\hline \multirow[b]{3}{*}{ Compras do Período + Estoque inicial } & \multicolumn{4}{|c|}{ Critérios de Valoração dos Estoques } \\
\hline & \multicolumn{2}{|c|}{ PEPS } & \multicolumn{2}{|c|}{ CUSTO MÉDIO } \\
\hline & $\mathrm{R} \$$ & $7.300,00$ & $\mathrm{R} \$$ & $7.300,00$ \\
\hline (-) Estoque Final & $\mathrm{RS}$ & 750,00 & $\mathrm{RS}$ & 674,00 \\
\hline (=) CMV & $\mathrm{R} \$$ & $6.550,00$ & $\mathrm{R} \$$ & $6.626,00$ \\
\hline Valor de Vendas do Período & $\mathrm{RS}$ & $10.000,00$ & $\mathrm{R} \$$ & $10.000,00$ \\
\hline (=) Lucro Bruto & $\mathrm{RS}$ & $3.450,00$ & $\mathrm{RS}$ & $3.374,00$ \\
\hline
\end{tabular}

Fonte: Autoria própria

Para a apuração do Lucro Bruto das operações é necessário que seja aplicado a fórmula do Custo das mercadorias vendidas (CMV) que é : $\mathrm{CMV}=\mathrm{EI}+\mathrm{CP}-\mathrm{EF}$, onde El corresponde ao estoque inicial, CP compras do período e EF estoque final. No exemplo acima foi considerado o estoque inicial igual a zero e um total de receitas com vendas no valor de $\mathrm{R} \$ 10.000,00$.

Pelo critério PEPS evidencia-se um lucro bruto maior, pois na sua metodologia de apuração considera-se: o primeiro item que entra no estoque será o primeiro a sair, portanto os valores constantes no estoque final tendem a ficar mais próximos dos valores das compras mais recentes. Já pelo critério do Custo Médio, notabiliza-se um lucro abaixo do apurado no PEPS, pelo motivo de seus estoques manterem-se sempre na média aritmética, em que a cada compra calcula-se um novo preço médio do item que será utilizado nas vendas subsequentes da entidade. (PADOVEZE, 2014).

\subsubsection{IMPACTO ECONÔMICO}

Na Dimensão Econômica cada departamento/área que compõem a entidade deve ser tratada como se fossem independentes, desta forma, será possível uma análise

RC: 100873

Disponível em:

https://www.nucleodoconhecimento.com.br/contabilidade/movimentacao-deestoques 
dos resultados individuais e objetivos em comum entre elas, dando, desta forma, ao gestor ferramentas necessárias e assertivas na administração dos recursos consumidos como custos e despesas de cada área.

Do ponto de vista de Silva (2019), para que a entidade atinja o fim desejado, ou seja, bons resultados, é vital que haja reunião de esforços e comprometimento não somente na gestão de estoques, mas também na gestão de compras, na gestão de recebimento, na gestão da expedição, ou seja todos intensificando esforços no objetivo comum da empresa.

\subsubsection{IMPACTO PATRIMONIAL}

Quanto ao quesito patrimonial, da aquisição a posse, o estoque é um bem, um patrimônio da instituição e toda a ação advinda do tratamento dos estoques gera consequências nessa dimensão, cada movimento operacional, cada decisão financeira e administrativa, os resultados econômicos gerados e esperados vão repercutir precisamente no âmbito patrimonial, cabe então a gestão tomar decisões que possibilitarão, por exemplo, um bom giro dos estoques para que estes cumpram o seu papel de garantir um balanço patrimonial positivo e a plena funcionalidade do empreendimento.

Segundo Silva (2019), para que a entidade possa garantir uma boa eficácia no processo de gestão, ela terá que garantir um bom monitoramento dos itens do balanço patrimonial (ativos, passivos e patrimônio líquido), principalmente os de estoque, devido às consequências/impactos que eles podem trazer para o patrimônio. Por exemplo, uma compra volumosa de determinada mercadoria sem a devida projeção de suas vendas pode ocasionar obsolescência do estoque ou estoque "parado" por muitos períodos, portanto, esta análise é de suma importância ao gestor de estoques, bem como suas decisões.

\section{MATERIAIS E MÉTODOS}

RC: 100873

Disponível em:

https://www.nucleodoconhecimento.com.br/contabilidade/movimentacao-de$\underline{\text { estoques }}$ 


\subsection{PROCEDIMENTOS METODOLÓGICOS}

Segundo Fonseca (2012), os procedimentos metodológicos são responsáveis por dirimir as melhores técnicas e ferramentas que serão utilizadas na pesquisa, com o objetivo de nortear o trabalho no atingimento dos resultados esperados.

\subsubsection{QUANTO À NATUREZA}

Quanto à natureza, a pesquisa é qualitativa, devido às características de sua abordagem, os quais envolvem os estoques e como uso adequado favorece uma gestão assertiva nas entidades. De acordo Zambello et al. (2018), a pesquisa qualitativa é utilizada quando se busca descrever a variedade do problema proposto, em que o processo não requer o uso de métodos e técnicas estatísticas na elucidação dos fatos que os concluem. Do ponto de vista de Prodanov e Freitas (2013), o processo e seu significado são os focos principais de abordagem.

\subsubsection{QUANTO AOS FINS}

Do ponto de vista de seus objetivos, a pesquisa é explicativa, pois, através dela houve a elucidação sobre a forma de como os estoques podem ser tratados. Nesse sentido, foram identificadas as situações/fenômenos nas quais as empresas estão sujeitas e como devem controlar esse ativo tão importante, garantindo, desta forma, a otimização nos resultados da entidade. Conforme GIL (2010), pesquisa explicativa é quando o pesquisador procura os porquês das coisas e causas, por meio do registro, da análise, da classificação e da interpretação dos fenômenos observados. Visa a identificar os fatores que determinam ou contribuem para a ocorrência dos fenômenos. De acordo com Severino (2013), busca também a identificação de possíveis causas, sejam elas compreendidas pelo método experimental ou qualitativo.

RC: 100873

Disponível em:

https://www.nucleodoconhecimento.com.br/contabilidade/movimentacao-deestoques 


\subsubsection{QUANTO AOS MEIOS}

Para Marconi e Lakatos (2017), a pesquisa bibliográfica é aquela em que se busca nas obras o levantamento, seleção e análise de dados para interpretá-los. Para esta pesquisa também foi utilizado o CPC (Comitê de Pronunciamentos Contábeis), além dos artigos científicos, periódicos, monografias, teses etc., relacionados ao tema proposto capaz de prover sustentação técnica necessária para a construção da pesquisa. O escopo do artigo está estruturado a partir dos objetivos mencionados que ajudaram a elucidar o problema apresentado, para isso foi utilizado de forma organizada os meios metodológicos necessários para se chegar à finalidade desejada. Para Fonseca (2012), é necessário não somente coletar os dados nos documentos tornados públicos e sim ressignificá-los, como por exemplo, em novas abordagens e conclusões sobre a temática apresentada.

\section{CONSIDERAÇÕES FINAIS}

Conforme disposto, a gestão de estoques envolve aspectos como: ativos, capital de giro, geração de receitas, itens atrelados ao equilíbrio frente às demandas de mercado, funcionamento e competitividade da entidade, movimentação interna, que abrange o processo de aquisição até a venda. Todos esses mecanismos são características relevantes para o estudo dos estoques.

Quanto aos objetivos dispostos neste artigo, e devido ao caráter bibliográfico do mesmo, através da análise de diversos conteúdos que tratam a respeito da movimentação, do controle e da valoração dos estoques foi possível compreender a dinâmica que estes estão envolvidos. Através da aplicação do método PEPS ou Custo Médio toda a movimentação e controle dos estoques pode ser observada e medida e irão gerar informações que servirão de base para tomadas de decisão e administração repercutindo por toda a entidade.

A questão que norteou este trabalho, que é como controlar os estoques e em que dimensões dentro das entidades eles causam impactos, foi respondida da seguinte RC: 100873

Disponível em:

https://www.nucleodoconhecimento.com.br/contabilidade/movimentacao-de$\underline{\text { estoques }}$ 
maneira, os estoques são uma das válvulas chaves para o pleno funcionamento das organizações que os utilizam, seu controle é inerente e a forma como deve ser feito deve ser aquela que se adeque ao melhor funcionamento da entidade, deve ser tratada pontualmente e de maneira eficiente, que como foi abordado no artigo, irão gerar impactos econômicos, financeiros, operacionais e patrimoniais.

Assim, dos questionamentos destacados ao longo desse trabalho em relação a análise bibliográfica, meio de controle e valoração e de que forma os estoques incidem em diferentes dimensões dentro de uma entidade, com a contextualização destes itens do conteúdo disponibilizado pelos autores citados, foi possível explanálos e estudá-los.

O estoque então é algo de vital importância para uma entidade que deles necessitam, assim, o seu tratamento deve ser feito da melhor forma possível, a fim de que a sua função seja aplicada para otimizar o desempenho da empresa no mercado. Desta forma, objetiva-se, por fim, que esse artigo possa servir de base para futuros trabalhos que enriqueçam ainda mais o tema tratado.

\section{REFERÊNCIAS BIBLIOGRÁFICAS}

ALMEIDA, M. C. Curso de contabilidade intermediária em IFRS e CPC. São Paulo: Atlas, 2014.

CPC. Comitê de Pronunciamentos Contábeis: pronunciamento técnico CPC 16(R1) - Estoques. Brasília - DF, 2009. Disponível em: <http://static.cpc.aatb.com.br/Documentos/243_CPC_16_R1_rev\%2013.pdf>. Acesso em: 25 de março de 2021.

BRASIL. DECRETO № 9.580, DE 22 DE NOVEMBRO DE 2018. Brasília - DF. Disponível em: <http://www.planalto.gov.br/ccivil_03/_ato20152018/2018/decreto/D9580.htm> Acesso em: 09 de Setembro de 2021 
FERREIRA, R. J. Contabilidade Avançada: teoria e questões comentadas conforme Lei 12.973/2014 e pronunciamentos do CPC. 7. ed. Rio de Janeiro: Editora Ferreira, 2014.

FONSECA, R. C. V. da. Metodologia do trabalho científico. 1. Ed. Curitiba: IESDE Brasil, 2012.

GELBCKE, E. R. et al. Manual de contabilidade societária: aplicável a todas as sociedades, de acordo com as normas internacionais e do CPC. 3.ed. São Paulo: Atlas, 2018.

GIL, A. C. Como elaborar projetos de pesquisa. 5. ed. São Paulo: Atlas, 2010.

IUDÍCIBUS, S. de; MARION, J. C. Contabilidade Comercial: atualização conforme Lei no 11.638/07 e Lei no 11.941/09. 9.ed. São Paulo: Atlas, 2010.

MARCONI, M. de A.; LAKATOS, E. M. Fundamentos de metodologia científica. 8.Ed. São Paulo: Atlas, 2017.

MARION, J. C. Introdução à contabilidade com ênfase em teoria. 2. ed. Campinas: Alínea, 2013.

MARTINS, F. Curso de direito comercial. 38. ed. Ver., atual e ampliada. Rio de Janeiro: Forense, 2015

PADOVEZE, C. L. Manual de contabilidade básica: contabilidade introdutória e intermediária. 9. ed. São Paulo: Atlas, 2014.

PAOLESCHI, B. Almoxarifado e gestão de estoques. 3.ed. São Paulo: Érica, 2019.

PAOLESCHI, B. Cadeia de suprimentos. 1.ed. São Paulo: Érica,2014.

RIBEIRO, O. M. Contabilidade de Custos. 2. ed. São Paulo: Saraiva, 2011.

$\mathrm{RC}: 100873$

Disponível em:

https://www.nucleodoconhecimento.com.br/contabilidade/movimentacao-deestoques 
SEVERINO, A. J. Metodologia do trabalho científico. 1. ed. São Paulo: Cortez, 2013.

SILVA, B. W. Gestão de Estoques: planejamento, execução e controle. 2.Ed. João Monlevade: BWS Consultoria, 2019.

SILVA, G. G. R. da. Gestão de estoques e armazenagem. São Paulo: Senac, 2018.

SILVA, R. N. S.; LINS, L. dos S. Gestão de custos: contabilidade, controle e análise. 3.ed. São Paulo: Atlas, 2014.

VIEIRA, H. F. Gestão de estoques e operações industriais. Curitiba: IESDE, 2009.

ZAMBELLO, A. V. et al. Metodologia da pesquisa e do trabalho científico. 1. ed. Penápolis: FUNEPE, 2018.

Enviado: Outubro, 2021.

Aprovado: Novembro, 2021.

RC: 100873

Disponível em:

https://www.nucleodoconhecimento.com.br/contabilidade/movimentacao-deestoques 